\title{
Surgical History Presents in the Emergency Department
}

Glenn Patriquin

Class of 2012, Faculty of Medicine, Dalhousie University

$\mathrm{T}_{\mathrm{p}, \mathrm{h}}^{\mathrm{h}}$ he routine emergency department presentation of a patient in his mid-seventies, with shortness of breath and other related difficulties introduced me to an important aspect of "obsolete" infectious disease history. As I was absent for his physical examination, my first visual representation of the patient's thorax came in the form of an x-ray. The image revealed a very obvious distortion of his ribcage and chest wall containing a lung that was drastically shrunken in size. A member of the health team immediately recognized that this was the result of a thoracoplasty - the unilateral removal of several ribs and the subsequent collapse of the thoracic wall and of a single lung. The procedure (among a group of treatments known as 'collapse therapy') was once a treatment option for those with tuberculosis, before the widespread use of antibiotics.

As reviewed by Rosenblatt, a school of physicians in the mid-1800s were impressed by the observation that some people with lung disease who sustained a spontaneous pneumothorax (the introduction of air into the pleural space) would experience some improvement in their health. ${ }^{1}$ Physicians found that closing off the lesions resulting from a tuberculosis infection (often near the apex of the lung) from respiration would allow for some lung recovery and would limit the progression of the disease. This led to the development of a procedure involving deliberately injecting air into the pleural space (thus creating an artificial pneumothorax), though it took some time before this procedure became commonly practiced. In the Nova Scotia Sanatorium in Kentville, NS (a hospital for the treatment of tuberculosis), doctors began performing artificial pneumothoraces in 1914, and continued until $1954 .^{2}$ Thousands of procedures were performed across the country, with pneumothoraces accounting for almost one third of Canadian sanatorium tuberculosis surgeries in 1937. ${ }^{3}$ Unfortunately, a pneumothorax was only a temporary treatment, so patients underwent repeated artificial pneumothoraces in order to maintain the collapse. ${ }^{4}$ Though the procedure was said to be painless ${ }^{5}$, it did require that the patient undergo potent fluoroscopy before and after each air injection, visualizing the lung to ensure proper outcome of the procedure - a necessity that time proved to have cancerous consequences for some patients. ${ }^{2}$
The rationale that led to induced pneumothoraces as a treatment for tuberculosis also influenced the introduction of more permanent forms of collapse therapy. As in the case of the emergency department patient above, thoracoplasty was used as a permanent treatment that would not allow the lung to regain its original size and capacity, limiting the advancement of the disease. This procedure involved the removal of several (usually superior) ribs from the ribcage. Generally 7-8 ribs would be removed through a series of surgeries (2-3 ribs per operation). ${ }^{6}$ The first Canadian thoracoplasty for the treatment of tuberculosis was performed in 1912 by Edward Archibald, head of surgery at McGill University. ${ }^{4,6}$ Thoracoplasties to treat tuberculosis became obsolete in Canada in the early 1960s when resection of affected lung tissue became a reliable surgical treatment. ${ }^{6}$ Our emergency department patient was thought to have likely been treated surgically for tuberculosis in the 1950s (with obvious success).

The evolution of collapse therapy led to the practice of plombage - the introduction of inert materials under the ribcage to specifically target the superior portion of the lung, closing off the lung cavities resulting from the mycobacteria infection. ${ }^{7}$ There were several major advantages of plombage over thoracoplasty, both medical and psychological. Plombage could be performed in one surgery as opposed to three or four required for thoracoplasty, ${ }^{6}$ and the patient's stay in hospital was lesser for a plombage procedure than a thoracoplasty. ${ }^{7}$ Plombage preserved more lung function, it could be used to treat bilateral disease, and it could be used on patients who had other health concerns that made thoracoplasty risky. ${ }^{7}$ Perhaps the most important psychological advantage of plombage over thoracoplasty was the avoidance of a permanent physical deformity. Plombage was performed using a variety of materials over its evolution, including fat, bone, wax, rubber, fiberglass, and synthetic spheres. ${ }^{7}$ This procedure was not without complications. Early problems included breach of lesion (leading to the spread of tuberculosis infection), obstruction of the superior vena cava, hemorrhage, non-tuberculosis infection, and migration of the materials. ${ }^{7,8}$ Patients were also at long-term risk for the development of fistulas (bronchopleural or cutaneous), irritation of the brachial plexus, and the development of sarcomas in association with the inserted materials. ${ }^{7,8}$ 
Other collapse therapies performed in the pre-antibiotic tuberculosis era consisted of unilaterally elevating the diaphragm to reduce the volume in one side of the thorax. In 1952, Montreal physician Joseph Yeh reported, "It is an interesting fact observed not infrequently that tuberculous pregnant women show improvement in their pulmonary lesions during their gestations." 9 He went on to mention the hypothesis (among other hypotheses) that the enlarging fetus elevated the diaphragm and thus reduced the thoracic space for lung expansion. Clinical displacement of the diaphragm was achieved mainly by two methods, sometimes used in combination with other collapse therapies — induced pneumoperitoneum and phrenicotomy. Pneumoperitoneum is the introduction of air into the abdominal cavity, forcing the diaphragm upward and reducing the space in the thorax. The procedure was more suited to (the less common) lesions of the lower $2 / 3$ of the lung than was a thoracoplasty (which was most effective for lesions located at the lung apex). ${ }^{10}$ It was a simple procedure in which $400-700 \mathrm{cc}$ of air was injected into the abdominal cavity (with repeated weekly injections of up to $1000 \mathrm{cc}$ ). The pneumoperitoneum, however, was rather non-specific and would cause a slight elevation of the diaphragm bilaterally.

Often a pneumoperitoneum was coupled with a phrenicotomy (or phrenicolysis) - the unilateral crushing or division of the phrenic nerve. ${ }^{4}$ Inactivating the diaphragm meant that it would no longer expand inferiorly with inspiration. This limited the expansion of the lung on the treated side, providing a path of least resistance for the abdominal air. ${ }^{10}$ The superintendant and a surgeon at the Nova Scotia Sanatorium reported in 1939 that their institution was second to only one other sanatorium in the country in terms of the number of phrenic nerve operations performed. ${ }^{3}$ Within the period of 1930 to 1937, 250 such operations took place in Kentville, approximately $75 \%$ of them leading to a permanent destruction of the diaphragm function of the treated side.

Are thoracoplasty and similar surgical interventions for tuberculosis now a representation of historical infectious disease treatment, or are these treatments that a new generation of physicians will commonly recommend and perform? We may hypothesize that with an increasing incidence of antibiotic resistance, we could quite possibly find ourselves in clinical situations that mimic the 'pre-antibiotic era.' Indeed, collapse therapy has been used recently for the treatment of multidrug resistant mycobacterium infections ${ }^{11}$ and when lung damage was too extensive for resection. ${ }^{12}$ At the very least, current physicians and medical students must be aware of past treatments (not only of tuberculosis) in order to anticipate presentations of associated complications even decades later. ${ }^{13}$ As important as it is for medical professionals and students to stay abreast of current medical and surgical treatments, one must also appreciate the importance of recognizing treatments of the past and how their remnants might influence treatment for diseases today. Given the relatively short time elapsed since the use of these 'obsolete' surgeries, and the sheer numbers performed, it is possible that many of us will experience treating those with the marks of tuberculosis history.

\section{REFERENCES}

1. Rosenblatt MB. Pulmonary tuberculosis: Evolution of modern therapy. Bull N Y Acad Med 1973;49:163-196.

2. Myrden JA, Hiltz JE. Breast cancer following multiple fluoroscopies during artificial pneumothorax treatment. Can Med Assoc J 1969;100:1032-1034.

3. Miller AF, Schaffner VD. The results of phrenic nerve paralysis in the treatment of pulmonary tuberculosis. Can Med Assoc J 1939;40:55-63.

4. Grzybowski S, Allen EA. Tuberculosis: 2. History of the disease in Canada. Can Med Assoc J 1999;160:1025-1028.

5. Jeanes CWL. The Toronto Free Hospital for Consumptive Poor. Can Med Assoc J 1992;147:844.

6. Holtslander G, Lagasse D, Loewen V, Rutherford S. "Tuberculosis history in Canada." Canada's fight against TB. <http://www.lung.ca/tb.html > (4 January 2009).

7. Shepherd MP. Plombage in the 1980s. Thorax 1985;40:328-340.

8. Thomas GE, Chandrasekhar B, Grannis FW. Surgical treatment of complications 45 years after extraperiosteal pneumonolysis and plombage using acrylic resin balls for cavitary pulmonary tuberculosis. Chest 1995;108:1163-1164.

9. Yeh JCC. Pneumoperitoneum in the treatment of pulmonary tuberculosis - A review of 190 cases from 1944 to 1950. Can Med Assoc J 1952;66:553-556.

10. Lyons FW. Pneumoperitoneum therapy in lower zone tuberculosis. Chest 1949;16:21-28.

11. Dewan RK, Singh S, Kumar A, Meena BK. Thoracoplasty: An obsolete procedure? Indian J Chest Dis Allied Sci 1999;41:83-88.

12. Jouveshomme S, Dautzenberg B, Bakdach H, Derenne J-P. Preliminary results of collapse therapy with plombage for pulmonary disease caused by multidrugresistant Mycobacteria. Am J Respir Crit Care Med 1998;157:1609-1615.

13. Ibarra-Perez C, Kelly-Garcia J. Lung carcinoma in a patient with lucite sphere plombage thoracoplasty. Chest 1994;105:1622-1623. 


\section{Congratulations 2009 Graduates}

Evergreen Home for Special Care is a privately owned accredited facility that provides long term and respite care for senior residents and special needs children.

Our mission is to provide holistic care that meets or exceeds the needs and expectations of our residents.

For more information or career opportunities, please visit our website www.evergreenhome.ns.ca

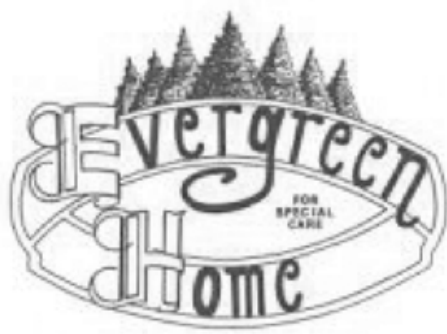

"We believe our first responsibility is to the doctors, nurses and patients, to mothers and fathers and all others who use our products and services.

In meeting their needs everything we do must be of high quality."

- From the Jolinson \& Johnson Credo

\section{Guysborough Antigonish Strait Health Authority}

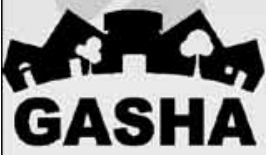

"Working Together For a Healthy Community"

Guysborough Antigonish Strait Health Authority serves a population of over 45,000 residents in Antigonish, Guysborough, Inverness and Richmond counties in picturesque Nova Scotia.

Our District includes five healthcare facilities in Antigonish, Canso, Guysborough, Evanston and Sherbrooke. We also have shared services in Addictions, Mental Health and Public Health. GASHA is home to St. Francis

Xavier University, a campus of the Nova Scotia Community College and has the first accredited District Trauma Centre in Nova Scotia.

Living and working in rural Nova Scotia comes with many benefits. Smaller communities mean closer relationships with fellow physicians, staff and local residents while still maintaining close proximity to the major centres within the Province.

GASHA offers a competitive recruitment package and provincial incentives for physicians. We invite you to come and check out our lifestyle; you will not be disappointed.

Contact:

Dr.Jeremy Hillyard

District Chief of Staff

Guysborough Antigonish Strait Health Authority

(902) $867-4170$

DrJeremy.Hillyard@gasha.nshealth.ca 